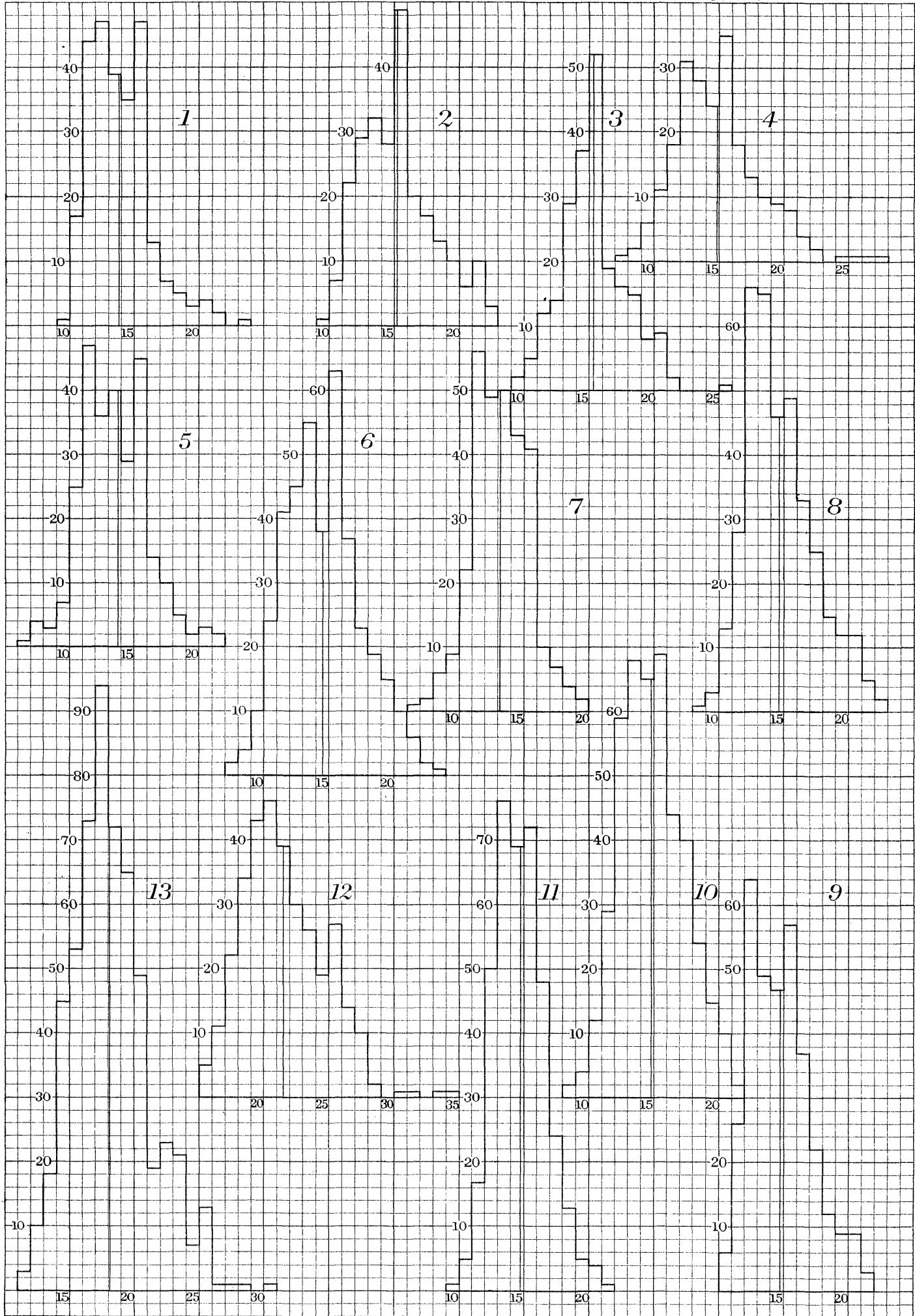




\section{Variation in the Ray-flowers of some Compositae.}

By

K. Koriba.

With Plate $V$.

It is of some interest to investigate, how the meristic change of multiple organs is affected by the enviromental and seasonal conditions, and to what extent does the series of $\mathrm{FiBONACCI}^{1)}$ in the occurrence of variates hold.

Last summer I have counted, for the study, the number of rays of three Compositae, namely Arnica unalaschcensis Less. on Mt. Hakkoda, and Aster trinervius RoxB. var. congestus Fr. et SAv. and Asteromaea indica BL. var. pinnatifida MAxiм. in Aomori. The results will be presented in the following pages.

\section{Arnica unalaschcensis Less.}

The plant is found growing abundantly among the alpine vegetation of Mt. Hakkoda (1852 m.), especially in the western inner wall of the ancient crater on the summit and along the eastern slope of the peak.

Here one should notice two factors that may have some definite relation to the condition of variation. The one is that the plant sends out only one head from its perennial root, and the other is the difference of thawing of snow by different parts of the mountain.

There is different significance of the seasonal variation of rays, according to whether the plant has only one head or many. In the multicipital Compositae, the plant itself may

1) LudwiG, Weiteres über Fibonaccikurven. Bot. Centralbl. Bd. 68, 1896, p. 7 . 
show the seasonal change without any disturbance of the enviromental conditions, for the velocity of development of heads and the corresponding meristic change of their rays depend on their position in branches. This is perhaps due to the difference of distribution of nourishment, and so the earlier the head blossoms, the larger is the number of parts, and vica versa. ${ }^{1)}$

But we should still consider the external influences, especially that of the climatic change, which evidently must affect the organs in its early stage of development. ${ }^{2)}$ And if a change has thus occurred in one part of a plant by an external cause, this again introduces the disturbance to all other parts of branches where the organs are not yet formed, in such a way as it was called the correlative mosaic work by HAAcke. ${ }^{3)}$

Thus in the multicipital Compositae, the inner tendency of variation of rays is intricately affected by the fluctuation of external factors, so that, unless we treat only with the primary heads, the influence of each factor on the variation is not easy to determine. On the other hand in the single-headed Compositae, the head being representative of that individual stock, not only the variation of rays, but also the deviation of flowering season must depend entirely on the external conditions, so that, if we know the actual conditions, we can compare the results hand in hand with them.

In the case of Arnica unalaschcensis the difference of snowthawing by different parts of the mountain as was already mentioned - in the peak of such a height it thaws from up to downward, from slope to valley - is one of the great factors which determines not only the flowering season, but also the vigorousness of plants. The earlier the snow thaws; - the earlier it blossoms and the longer is the duration of growth

1) DE VRIES, Mutationstheorie. Bd. I, Leipzig, 1901. p. 544-5. SHuLl, A quantitative Study of Variation in the Bracts, Rays, and Disc Florets of Aster Shortii etc. Amer. Nat. Vol. 36, 1902, p. 150.

2) De VRIES, l.c. p. 99, 371.

3) HAACKE, Entwickelungs-mechanishe Untersuchungen. I. Über numerische Variation typischer Organe and korrelative Mosaikarbeit. Biol. Centralbl. Bd. 16, 1896, p. 496. 
in every year, and so the more vigorous is the plant. Indeed, in spite of its single-headedness, ${ }^{1)}$ there was so remarkable a difference in flowering season that we could see the yellow heads for more than fourty days.

In addition to this, there are still other factors to be noticed, namely the fertility of soil and the general condition of vegetation. I have selected for the collection three places where the plant predominantly grows, namely the western inner wall of the crater, and the estern radial valley of the peak and its northern slope, the former including the area of about 20 to $60 \mathrm{~m}$., and the latter two, of about 100 to $250 \mathrm{~m}$. below the summit. I will call hereafter these three places, the crater, the valley and the slope. In the crater and the valley there can be found no perceptible difference of vegetation, but on the slope, which is the northern border of the valley, (its southern border is densely covered by bamboo-grasses) the vegetation is very poor. Its upper part is occupied by a scanty growth of bamboo-bushes, and its lower part; on account of snow-slip, is almost sterile, exposing the greater part of the naked volcanic detritus, so that a glance on the plants growing there gives clearly the impression of weaker growth.

Arnica unalaschcensis is thus a very interesting object for the study of variation, being indifferent to the seasonal and corresponding meristic changes of rays on account of its singleheadedness, and its growing region being subjected to two conditions, namely the regular progression of snow-thawing and the fertility of soil, the former of which being the principal condition for the change of flowering season. And it is more likely to gain valuable results from the collection of material under known conditions than from at-random collection, as SHuLL already mentioned. ${ }^{2)}$

I visited these places for the collection four times within a month. On my first visit on July 29 , I found the plants in full

1) Seven specimens were found with one or two lateral heads throughout my collections. They were seen with very small number of rays in their lateral heads, and such stocks were rejected from the material used.

2) SHulL, l.c. p. 150 . 
bloom in the crater, but in the valley and slope, they were just beginning to flower, and the collection was made only in the first place. Among the specimens collected, I have counted only the healthy, fully blossomed heads, and those which have been injured mechanically or by insects were rejected. Results obtained are as follows : ${ }^{1)}$

First collection. July 29. Lot No. 1 (Crater).

\begin{tabular}{|c|c|c|c|c|c|}
\hline$n$ & $A$ & $\sigma$ & $C$ & Range & Mode \\
\hline 265 & 14.389 & 2.348 & 16.32 & $10-24$ & 16,13 \\
\hline
\end{tabular}

Further details are given in Table I. The rays in 265 heads were counted, and were found to vary in number from 10 to 24 , but the larger number of variates fell on classes 12 to 16 (P1. V Fig. 1), with equally developed modes on 13 and 16, either of which being a member of the Fibonacci-series. ${ }^{2)}$ The number of variates on class 12 was a little less than that on 13 , and that on 15 formed a sinus.

A week later, on my second visit, sufficient specimens were obtained both in the crater and valley, but on the slope only a few heads were in bloom amongst the scanty bamboo-bushes in the upper part, and no material was collected here. From those two lots the following results were obtained:

1) The notations and calculations of the statistical data are based on DAvENPORT's "Statistical Methods with special Reference to Biological Variation." 2. Ed. New York, 1904. where

$$
\begin{aligned}
& n=\text { number of variates, } \\
& A=\text { average or mean, } \\
& \sigma=\text { standard deviation, and } \\
& C=\text { coefficient of variability }\left(\frac{\sigma}{A} \times 100 \%\right) .
\end{aligned}
$$

2) After LuDwra the number of parts of multiple organs has a tendency to fall on either of the series $3,5,8,13,16,(=2 \times 8), 18(=5+13), 21,24(=3 \times 8), 26$ $(=2 \times 13), 29(=8+21), 34$, etc. See LudwıG, Über Variationskurven. Bot. Centralbl. Bd. 75. p. $97-10 \bar{T}, 178-183,1898$. 
Second collection. Aug. 5 .

\begin{tabular}{|c|c|c|c|c|c|c|}
\hline & $n$ & $A$ & $\sigma$ & $C$ & Range. & Mode \\
\cline { 2 - 7 } Lot No. 2 (crater) & 247 & 15.741 & 2.835 & 18.01 & $10-23$ & 16,14 \\
$" \quad, \quad 3$ (valley) & 221 & 15.878 & 2.524 & 15.90 & $10-26$ & 16 \\
\hline
\end{tabular}

In lot No. 2. (Fig. 2) the range was nearly equall to that of the former collection, but the higher frequency on 12-14 of the former was much lowered here, leaving only a slight mode on 14 (not on 13), and the mode on 16 was strongly developed, $19.8 \%$ of variates falling into that class. The variates on and above 17 were also more or less increased. Both the mean and coefficient of variability were therefore greater than the former.

In that of the valley (Fig. 3) the mode rose on 16 still more eminently, including $23.5 \%$ of the variates in it - the greatest of all the lots. The lower variates decreased more and more, especially on 11 to 13 , and no mode was seen. Of the higher variates, that on 17 to 19 are relatively larger in number, and the other abruptly decreased, but with the extremity on 26. The frequency-polygon tended thus to the monomodal symmetry. The mean was slightly greater than that of the lot No. 2, and it was the maximal value through all the lots. The standard deviation has, on account of the monomodal condition, decreased so much, that the coefficient of variability was the least of all the lots. 